\title{
Exploring sibling attitudes towards participation when the younger sibling has a severe speech and language disability
}

\author{
M Hansen, ${ }^{1} \mathrm{M}(\mathrm{AAC}) ; \mathbf{M}$ Harty, ${ }^{1,2} \mathrm{PhD} ; \mathbf{J}$ Bornman, ${ }^{1} \mathrm{PhD}$ \\ ${ }^{1}$ Centre for Augmentative and Alternative Communication, University of Pretoria, South Africa \\ ${ }^{2}$ Division of Communication Sciences and Disorders, University of Cape Town, South Africa
}

\section{Corresponding author: J Bornman (juan.bornman@up.ac.za)}

\begin{abstract}
Background. Typically developing children who have a younger sibling with a disability often feel inadequately supported and excluded from family interactions. However, early intervention programmes often use family activities and routines as intervention settings. Siblings' negative attitudes towards participation in such activities may therefore hamper intercession efforts.

Objective. To determine the attitudes of typically developing children toward their younger siblings with severe speech and language disabilities in four everyday life situations identified by the World Health Organization's International Classification of Functioning, Disability and Health: Children and Youth Version, namely communication, domestic life, interpersonal interaction and relationships, and major life areas.

Methods. An adapted structured interview format was used to determine the attitude of the 27 participants, 6- to 10-year-old typically developing South Africans.

Results. Typically developing peers were most positive towards participation in play activities with their sibling with a disability. They were also positive towards participation in household tasks. They were less positive towards communication participation and least positive about participation in interpersonal relationships. A significant difference between certain components of attitudes was reported for three of the four domains.

Conclusion. The attitudes of typically developing children are generally positive towards participating with their younger siblings with severe speech and language disabilities. These results can be used to select activities for activity-based interventions and to guide interventions aimed at supporting the siblings of children with disabilities.
\end{abstract}

S Afr J Child Health 2016;10(1):47-51. DOI:10.7196/SAJCH.2016.v106i1.1046

Sibling relationships are one of the closest, strongest and most enduring relationships within the core family system, as they allow for sharing ideas and expressing feelings through experiences of loyalty, support and rivalry. ${ }^{[1,2]}$ Interactions among siblings provide (and remain) opportunities to learn many crucial social, emotional, cognitive and communication skills that are necessary for participation in everyday life. Furthermore, the attitudes of either of the siblings towards sibling interactions will influence their participation in everyday life situations.

In families where one sibling has a disability, the typically developing sibling(s) can act as enablers if they have a positive attitude towards their sibling with a disability and towards their participation in everyday family activities. ${ }^{[3]}$ Given the potential impact of a typically developing sibling's attitude towards participation on the functional outcomes of a child with a disability, it is important that these attitudes are investigated.

Literature suggests that typically developing siblings often feel inadequately supported and excluded from participating with the sibling with the disability, resulting in atypical family interaction and participation. ${ }^{[2,4]}$ Furthermore, they may feel excluded from their sibling's intervention ${ }^{[5]}$ and in these instances, sibling relationships may be viewed as a barrier to family-focused, activity-based intervention.

The World Health Organization ${ }^{[6]}$ provides a conceptual framework in the form of the International Classification of Functioning, Disability and Health: Children and Youth (ICF-CY) Version in terms of which children's participation can be explored. The ICF-CY operationalises participation in nine domains and views participation as a non-linear, dynamic process that results from interaction between the child and its environment. Participation can be assessed as frequency, i.e. 'being there', or as intensity, i.e. 'being engaged while being there, ${ }^{3}$ in other words, how the child interacts with the social and physical environment. There is an increasing body of evidence that critically evaluates the use of the ICF-CY framework in clinical settings for certain populations, e.g. children with speech and language disabilities. ${ }^{[8-10]}$ Current research is using the ICF-CY framework to identify some of the everyday activities and life situations that children frequently participate in, with a view to informing family-focused, activity-based intervention. ${ }^{[11]}$ Based on an examination of the everyday activities and life situations captured in the ICF-CY, empirical research indicates that professionals rate many of these situations as being important for children. ${ }^{[12]}$ Data from a study involving parents of preschool children who were receiving speech and language intervention, indicate that parents are more likely than professionals to describe intervention outcomes in terms of changes in their child's participation, ${ }^{[10]}$ which underscores the importance of using 'participation' as an outcomes measure in family-focused intervention. More importantly, however, parents emphasise that this participation is described as changes in engagement in everyday life situations such as play, socialisation with others, and behaviour at home and school. ${ }^{[10]}$ Therefore, current data show that the participation domain in the ICF-CY is helpful when describing changes in participation in the everyday life situations of young children with speech and language disabilities.

Evidence suggests that everyday life situations in families with young children can be identified from the following ICF-CY domains: communication, self-care, domestic life, interpersonal relationships and interactions, major life areas (play and education) and, to a lesser extent, community life. ${ }^{[12]}$ In spite of seminal works that acknowledge the role of siblings in the development of children with 
disabilities ${ }^{[2,4,13]}$ and that highlight the fact that siblings' perceptions may differ from those of adults, ${ }^{[1]}$ a literature search revealed a paucity of empirical data that describe the attitudes of siblings towards participating in everyday life situations with children with speech and language disabilities.

In this study we consequently used an adapted structured interview schedule format to determine the attitudes of typically developing children towards their younger siblings with severe speech and language disabilities in four everyday life situations, according to the ICF-CY, namely communication (chapter d3), domestic life (chapter d6), interpersonal interactions and relationships (chapter d7) and major life areas (chapter $\mathrm{d} 8$ ).

\section{Methods}

\section{Research design}

An exploratory descriptive design based on a structured interview schedule with the Talking Mats (Talking Mats Ltd, Scotland) visual framework was used (Fig. 1).

\section{Participants}

\section{Participant selection criteria}

All participants had to be English speaking, typically developing (not having had to repeat a year at school) children between the ages of 6 and 10 years. They had to have a younger sibling who attended a preschool for children with severe speech and language disability. Although South Africa (SA) has an inclusive education policy, the majority of children with disabilities who attend school still go to separate, 'special' schools for children with disabilities. The special needs preschool that was selected provides an integrated assessment, intervention and preschool environment for ambulatory children with severe speech and language delay and average intelligence quotient (IQ). All participants had to reside permanently with their sibling. The parents of 35 potential participants who met the selection criteria were requested to consent to their child's participation, of whom eight parents refused consent, which resulted in 27 parents consenting on behalf of their children. Assent was then sought from the children themselves, and all assented.

\section{Description of the participants and their siblings}

The mean age of the 27 participants ( 9 male, 18 female) was 8 years (range 6 - 10 years), while the mean age of their siblings (21 male, 6 female) was 5 years (range $3-8$ years). Age and gender differences were calculated for each of the sibling dyads, of whom nine were same gender ( 6 male-male, 3 femalefemale). The remaining 18 were mixed gender (15 dyads with a female participant and male sibling, and 3 with a male participant and

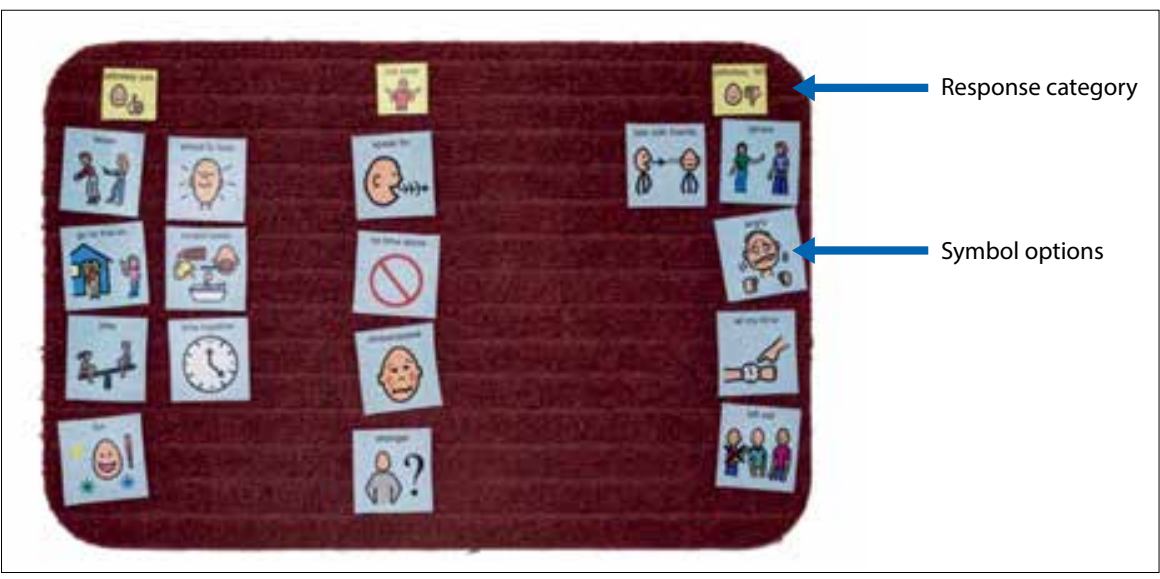

Fig. 1. Example of a completed Talking Mat.

female sibling). Despite their severe speech and language disability, all the siblings were ambulatory and displayed age-appropriate cognitive abilities, as stipulated by the admission criteria of the preschool they attended.

\section{Materials}

Two core theoretical constructs - attitude and participation - were used in the development of the interview items. Attitudes included three components, namely beliefs (the cognitive component) that often attract strong feelings (the affective component) and may then lead to specific actions (the behavioural component).$^{[14]}$ Participation was discussed in terms of the participation domains of the ICF$\mathrm{CY}$, namely major life areas, interpersonal relationships and domestic life. ${ }^{[10,12]}$ Data from these studies informed the selection of three typical everyday life situations with which siblings were bound to interact and that represented three different ICF-CY domains. Communication was added as an additional domain, as it was likely that the participants would have participation restrictions in this domain due to the nature of their sibling's disability. A preliminary set of 40 items that tapped into the affective, behavioural and cognitive aspects of attitude was developed (Table 1). ${ }^{[14]}$

An expert panel comprising three speechlanguage therapists, five remedial teachers and two occupational therapists with relevant experience subsequently evaluated the items and discarded nine of them. Picture communication symbols (PCSs) that visually depicted the specific item were developed for the remaining 31 items. All symbols were printed on cardboard, laminated and cut into $5 \mathrm{~cm} \times 5 \mathrm{~cm}$ squares. Velcro was attached to the back of each symbol for easy placement on a regular short-pile mat. A structured interview schedule was developed to ensure consistent presentation of the stimuli to each participant, thereby heightening procedural integrity.

\section{Procedures}

Data were collected by using a structured interview schedule based on the Talking Mats visual framework ${ }^{[15]}$ with a three-point response category: 'Definitely yes' (showing the PCS symbol of a thumbs up and a smiling face); 'Not sure' (showing the PCS symbol of a man shrugging his shoulders) and 'Definitely no' (showing the PCS symbol of thumbs down and a sad face). Talking Mats was developed to assist individuals to express their views or indicate their feelings. ${ }^{[15]}$ Each item on the structured interview schedule was read aloud and the matched PCS symbol was shown to each participant individually. When asked how they felt about each item, they indicated their choice by placing the matching PCS symbol under the relevant response category. After completion of all the items, the resulting Talking Mats image was captured with a digital camera. Fig. 1 shows an example of a completed Talking Mat. A series of three trial items was developed to ensure that participants understood the instructions and were able to complete the required task. Prior to the main study, a stringent pilot study was conducted with 30 Grade 1 learners with typically developing sibling(s) to ensure that the language level and suggested procedures were appropriate for the target population. The result was that minor modifications were made to the interview schedule. Next, a second pilot study was conducted with four children who matched the inclusion criteria for the study, which resulted in two items being reworded. ${ }^{[14]}$ No changes were necessary to the 31 items and the scripted interview remained unchanged.

\section{Ethical considerations}

The research adhered to ethical principles as stipulated by the Declaration of Helsinki, ${ }^{[16]}$ with ethics approval from the relevant university. Written informed consent was obtained from the principal, the preschool's board of trustees and the parents, followed by assent from the children themselves. 
Table 1. Everyday sibling life situations used in the development of the structured interview schedule

\begin{tabular}{|c|c|c|c|}
\hline Everyday life situations & Definition & Use & $\begin{array}{l}\text { Examples of items from the interview } \\
\text { schedule }\end{array}$ \\
\hline \multirow{3}{*}{$\begin{array}{l}\text { Communication } \\
\text { (ICF-CY } \\
\text { Chapter d3: } \\
\text { Communication) }\end{array}$} & \multirow{3}{*}{$\begin{array}{l}\text { Communication } \\
\text { participation is interactive } \\
\text { and reciprocal. Participants } \\
\text { exchange ideas, needs, } \\
\text { desires and information. It } \\
\text { forms the basis of human } \\
\text { interaction. }\end{array}$} & \multirow{3}{*}{$\begin{array}{l}\text { Items related to communication } \\
\text { participation (receptive } \\
\text { and expressive language) in } \\
\text { order to determine the typically } \\
\text { developing child's attitude } \\
\text { towards communication } \\
\text { participation with his/her sibling } \\
\text { with disability. }\end{array}$} & $\begin{array}{l}\text { Affective item: } \\
\text { 'I enjoy talking with my brother/sister' (\#A3) }\end{array}$ \\
\hline & & & $\begin{array}{l}\text { Behavioural item: } \\
\text { 'I ignore my brother/sister when I don't } \\
\text { understand him/her' (\#B2) }\end{array}$ \\
\hline & & & $\begin{array}{l}\text { Cognitive item: } \\
\text { 'My brother/sister understands everything I say' (\#C4) }\end{array}$ \\
\hline \multirow{3}{*}{$\begin{array}{l}\text { Household tasks } \\
\text { (ICF-CY } \\
\text { Chapter d6: } \\
\text { Domestic life) }\end{array}$} & \multirow{3}{*}{$\begin{array}{l}\text { Household tasks include } \\
\text { basic grooming activities, as } \\
\text { well as chores in and around } \\
\text { the house in which children } \\
\text { are expected to participate. }\end{array}$} & \multirow{3}{*}{$\begin{array}{l}\text { Items related to participation in } \\
\text { household tasks to determine } \\
\text { the typically developing child's } \\
\text { attitude towards participation } \\
\text { with his/her sibling with } \\
\text { disability in household tasks. }\end{array}$} & $\begin{array}{l}\text { Affective item: } \\
\text { 'I feel proud to be my brother/sister's helper' } \\
\text { (\#A8) }\end{array}$ \\
\hline & & & $\begin{array}{l}\text { Behavioural item: 'I help my brother/sister do } \\
\text { jobs around the house' (\#B6) }\end{array}$ \\
\hline & & & $\begin{array}{l}\text { Cognitive item: 'My brother/sister pretends to } \\
\text { struggle with easy tasks' (\#C8) }\end{array}$ \\
\hline \multirow{3}{*}{$\begin{array}{l}\text { Time and responsibility } \\
\text { situations } \\
\text { (ICF-CY } \\
\text { Chapter d7: } \\
\text { Interpersonal interactions } \\
\text { and relationships) }\end{array}$} & \multirow{3}{*}{$\begin{array}{l}\text { Interpersonal interactions } \\
\text { focus on establishing and } \\
\text { maintaining relationships. } \\
\text { Children with disabilities } \\
\text { often have limited peer } \\
\text { interaction opportunities, } \\
\text { thus their interpersonal } \\
\text { sibling interactions take on } \\
\text { increased meaning. }\end{array}$} & \multirow{3}{*}{$\begin{array}{l}\text { Items pertaining to joint } \\
\text { participation time, time alone } \\
\text { and time spent with parents } \\
\text { to determine the typically } \\
\text { developing child's attitude } \\
\text { towards time and responsibility } \\
\text { issues that relate to participation } \\
\text { with his/her sibling with } \\
\text { disability. }\end{array}$} & $\begin{array}{l}\text { Affective item: } \\
\text { 'I like spending time by myself sometimes' (\#A10) }\end{array}$ \\
\hline & & & $\begin{array}{l}\text { Behavioural item: } \\
\text { 'I want to spend more time alone with Mom and } \\
\text { Dad' (\#B5) }\end{array}$ \\
\hline & & & $\begin{array}{l}\text { Cognitive item: } \\
\text { 'Mom and Dad let me spend time by myself' } \\
(\# \mathrm{C} 11)\end{array}$ \\
\hline \multirow{3}{*}{$\begin{array}{l}\text { Play } \\
\text { (ICF-CY } \\
\text { Chapter d8: } \\
\text { Major life areas) }\end{array}$} & \multirow{3}{*}{$\begin{array}{l}\text { Play participation is regarded } \\
\text { as the vehicle for learning. It } \\
\text { provides an environment free } \\
\text { from pressure where children } \\
\text { learn about language, social } \\
\text { rules and interaction roles. }\end{array}$} & \multirow{3}{*}{$\begin{array}{l}\text { Items pertaining to play } \\
\text { and recreational activities } \\
\text { to determine the typically } \\
\text { developing child's attitude } \\
\text { towards play participation with } \\
\text { his/her sibling with disability. }\end{array}$} & $\begin{array}{l}\text { Affective item: } \\
\text { 'I like playing with my brother/sister' (\#A1) }\end{array}$ \\
\hline & & & $\begin{array}{l}\text { Behavioural item: } \\
\text { 'I always include my brother/sister in games I } \\
\text { play' (\#B1) }\end{array}$ \\
\hline & & & $\begin{array}{l}\text { Cognitive item: } \\
\text { 'My brother/sister enjoys playing with me' (\#C12) }\end{array}$ \\
\hline
\end{tabular}

\section{Data analysis}

The means procedure was employed to determine the mean score for participation in the four everyday life situations. Higher values indicated a more positive attitude. The Friedman two-way analysis of variance (ANOVA) ranked values were used to evaluate differences among the four situations: play (mean (SD) $2.72(0.24)$ ); participating in household tasks (mean 2.54 (0.22)); communication (mean 2.41 (0.21)); and interpersonal relationships (mean $1.96(0.29)$ ). SPSS (IBM, USA) compensated for the number of groups when the pairwise comparisons for the Friedman procedure were conducted and allowed a $5 \%$ level of significance for each pair. This procedure was repeated to evaluate differences in means among the affective, behavioural and cognitive components of attitudes for each of the everyday life situations.

\section{Results \\ Procedural integrity}

All sessions were video-recorded. Procedural integrity was determined for $20 \%$ of randomly selected completed interviews. A rating agreement of $97 \%$ was obtained, which indicated a high level of integrity.

\section{Comparisons across the four everyday life situations}

The 27 participants' attitudes towards participation in play were positive (mean $2.72(0.24)$ ). They also showed fairly positive attitudes towards participation in household tasks (mean 2.54 $(0.22)$ ) and in communication (mean $2.41(0.21)$ ). The participants were least positive about participation in interpersonal relationships (time and responsibility situations such as sharing parental attention), with a mean of $1.96(0.29)$. The results of the Friedman procedure, which evaluated differences in means among the four everyday life situations, were significant $\left(\chi^{2}(3)(N=27)=\right.$ $52.38, p \leq 0.0001$ ) (Table 2).

Follow-up pairwise comparisons were conducted. The null hypothesis was rejected if the $z$-value was larger than the critical $z$-value, where $1-\operatorname{PHI}(\mathrm{ZC})=\mathrm{ALPHA} /(\mathrm{K}(\mathrm{K}-1))$. The critical $z$-value for an alpha of 0.05 was 2.64 with four groups. The mean for play was significantly higher than the mean for communication $(z=3.27)$ and for interpersonal relationships (time and responsibility situations) $(z=6.96)$, although no statistically significant difference was observed between the mean values for play and participating in household tasks $(z=1.79)$. The mean for interpersonal relationships was significantly lower than for communication $(z=3.69)$, participation in household tasks $(z=5.17)$ and play $(z=6.96)$.

\section{Comparisons across the components of the sibling attitude scale}

The Friedman two-way ANOVA was conducted to explore how the three attitude components (affective, behavioural and cognitive) differed across the everyday life situations targeted in this study. The results of the Friedman test were significant for three of the four everyday life situations (Table 3 ). 
Table 2. Comparison of the attitude means obtained for the four everyday life situations $(N=27)$

\begin{tabular}{|c|c|c|c|c|c|c|c|c|}
\hline \multicolumn{2}{|c|}{$\begin{array}{c}\text { Communication } \\
\text { (ICF-CY } \\
\text { Chapter d3: } \\
\text { Communication) }\end{array}$} & \multicolumn{2}{|c|}{$\begin{array}{c}\text { Household } \\
\text { tasks (ICF-CY } \\
\text { Chapter d6: } \\
\text { Domestic life) }\end{array}$} & \multicolumn{2}{|c|}{$\begin{array}{l}\text { Time and } \\
\text { responsibility } \\
\text { situations (ICF- } \\
\text { CY Chapter d7: } \\
\text { Interpersonal } \\
\text { interactions and } \\
\text { relationships) }\end{array}$} & \multicolumn{2}{|c|}{$\begin{array}{c}\text { Play (ICF-CY } \\
\text { Chapter d8: Major } \\
\text { life areas) }\end{array}$} & \multirow[b]{2}{*}{$p$-value } \\
\hline Mean & SD & Mean & SD & Mean & SD & Mean & SD & \\
\hline $2.41^{\star b}$ & 0.21 & $2.54^{\mathrm{ab}}$ & 0.22 & $1.96^{c}$ & 0.29 & $2.72^{\mathrm{a}}$ & 0.24 & $<0.0001^{\dagger}$ \\
\hline
\end{tabular}

* Pairwise comparisons are significant at the $p \leq 0.05$ level in the instances where the means of life situations being compared do not contain the same postscript (e.g. communication and play).

${ }^{\dagger}$ Significant at the $p \leq 0.05$ level.

Table 3. Comparison between attitude components in the four everyday life situations $(N=27)$

\begin{tabular}{|c|c|c|c|c|c|c|c|}
\hline \multirow[b]{2}{*}{ Everyday life situations } & \multicolumn{2}{|c|}{ Affective } & \multicolumn{2}{|c|}{ Behavioural } & \multicolumn{2}{|c|}{ Cognitive } & \multirow[b]{2}{*}{$p$-value } \\
\hline & Mean & SD & Mean & SD & Mean & SD & \\
\hline $\begin{array}{l}\text { Communication } \\
\text { (ICF-CY } \\
\text { Chapter d3: } \\
\text { Communication) }\end{array}$ & $2.44^{\star a \mathrm{~b}}$ & 0.36 & $2.67^{\mathrm{a}}$ & 0.62 & $2.35^{\mathrm{b}}$ & 0.31 & $0.0316^{\dagger}$ \\
\hline $\begin{array}{l}\text { Household tasks } \\
\text { (ICF-CY } \\
\text { Chapter d6: Domestic life) }\end{array}$ & $2.89^{\mathrm{a}}$ & 0.29 & $2.79^{\mathrm{a}}$ & 0.32 & $1.81^{\mathrm{b}}$ & 0.57 & $0.0001^{\dagger}$ \\
\hline $\begin{array}{l}\text { Time and responsibility } \\
\text { situations } \\
\text { (ICF-CY } \\
\text { Chapter d7: Interpersonal } \\
\text { interactions and } \\
\text { relationships) }\end{array}$ & $1.99^{\mathrm{a}}$ & 0.33 & $1.74^{\mathrm{a}}$ & 0.94 & $2.04^{\mathrm{a}}$ & 0.55 & 0.2091 \\
\hline $\begin{array}{l}\text { Play } \\
\text { (ICF-CY } \\
\text { Chapter d8: Major life areas) }\end{array}$ & $2.84^{\mathrm{ab}}$ & 0.25 & $2.41^{\mathrm{a}}$ & 0.59 & $2.85^{\mathrm{b}}$ & 0.33 & $0.0176^{\dagger}$ \\
\hline
\end{tabular}

Follow-up pairwise comparisons were conducted for communication, play and household tasks. The null hypothesis was rejected if the $z$-stat was larger than the critical $z$-value, where $1-\mathrm{PHI}(\mathrm{ZC})=\operatorname{ALPHA} /(\mathrm{K}(\mathrm{K}-1))$. The critical $z$-value for an alpha of 0.05 was 2.39 with three groups. With regard to communication, the behavioural component was significantly higher than the cognitive component $(z=2.59)$. However, the affective component did not differ significantly from the behavioural component and neither did the affective and cognitive components differ. The analysis of the items related to participation in household tasks indicated a significant difference between the behavioural and cognitive component $(z=4.35)$ and also between the affective and cognitive components $(z=4.83)$, but not between the affective and behavioural components. Both the affective and behavioural components were higher than the cognitive component. In play, the results indicated that the cognitive component was significantly higher than the behavioural component $(z=2.59)$, but that there was no difference between the affective and behaviour components and neither between the affective and the cognitive components.

\section{Discussion}

The rating of the affective component was high for all the everyday life situations and no statistically significant difference was observed. Earlier research reported that siblings of children with disabilities displayed significantly more nurturing behaviours than siblings of children without disabilities, ${ }^{[17]}$ and that they were kinder and more positive toward their siblings with disability than toward their typically developing siblings. ${ }^{[4]}$ Similarly, Caro and Derevensky ${ }^{[18]}$ reported frequent displays of spontaneous affectionate behaviour during sibling interactions. Results from the present study concur with research evidence, which suggests that the presence of a disability within a sibling relationship increases the likelihood of a more positive sibling affect.

Rating the cognitive and behavioural components across the everyday life situations indicated a statistically significant difference between the behavioural and the cognitive components across three of the everyday life situations (play, communication and household tasks). The mean value for the cognitive component was higher than the behavioural component in both play and interpersonal relationships (time and responsibility situations such as sharing parental attention). The mean for the behavioural component was higher than the cognitive component for communication participation and participation in household tasks.

In exploring these results, it becomes necessary to incorporate the constructs of engagement and flow (as a measure of cognitive involvement). Participation in play as an everyday life situation requires high levels of engagement in activities that are intrinsically motivating and within the child's initial competence, experience and interests. ${ }^{[19]}$ Furthermore, play requires a high level of voluntary control, once again suggesting high levels of cognitive involvement in a functional context. The same holds true for interpersonal relationships (time and responsibility situations), which focus on establishing and maintaining relationships in the context of an individual's social roles. When determining the level of cognitive involvement in the everyday life situations of participating in communication interactions and household tasks, it becomes clear that both of these situations require lower levels of cognitive involvement, because the activities that establish these everyday life situations require more 'doing' (behavioural component) than 'thinking' (cognitive component). It was evident from the present study that a measure (such as an attitude measure) that expresses the degree of cognitive involvement in everyday life situations in an ICF-CY domain could be used to make recommendations in respect of family-focused, activity-based interventions.

Sibling relationships are one of the key relationships in which children acquire and develop many social and cognitive skills. If clinicians are able to identify specific everyday life situations in which cognitive involvement of both siblings is high, e.g. during play interactions, these situations could be used as contexts to coach older siblings to model specific communication strategies, e.g. key word signing or using augmentative and alternative communication systems and strategies. This would support 
acquisition and generalisation of skills facilitated by the clinician, as well as contributing to long-term, positive family outcomes, as the responsibility of supporting intervention will not rest solely on the parents, but on the family structure as a whole.

Furthermore, by identifying the attitudes of siblings in specific everyday life situations, barriers to and opportunities for positive outcomes can be more specifically identified and defined. This will enable the intervention team to make more appropriate and timely referrals and to structure intervention goals and supports accordingly.

\section{Study limitations}

A methodological limitation was the relatively small sample size and the fact that it was demographically limited (e.g. in terms of socio-economic status). Moreover, participants were selected by means of a convenience sample (i.e. selecting siblings of children in a preschool for children with severe speech and language disability). Therefore, further studies are needed in more demographically representative samples in SA to come to more general conclusions.

The comprehensive process of developing the adapted interview schedule, which included an in-depth pilot study, ${ }^{[14]}$ allowed the researchers to refine the language level and length of the schedule to suit the needs of the target population in this study. It is, however, important to mention that certain allowances had to be made to accommodate the age of the participants, which had an impact on the statistical analysis. For instance, a three-point scale had to be used rather than a four-point scale and a limited number of response items had to be used under each sub-section, all of which subsequently contributed to the unequal distribution of response items from the different participation domains.

\section{Conclusions}

The impact of certain sibling dyad characteristics (e.g. age, gender, severity of disability) on the attitude of typically developing siblings in everyday life situations has yet to be determined. However, data from the current study indicate that the attitudes of typically developing siblings towards participation with their younger siblings with severe speech and language disabilities are generally positive. The data also reveal that a measure (such as an attitude measure) which indicates the degree of cognitive involvement in everyday life situations in an ICF-CY domain may be used to describe participation. The identification of additional everyday life situations for young children with disabilities, in conjunction with their siblings' views of participation in these situations, can and should inform appropriate activity-based interventions for children with disabilities, as well as for sibling support programmes. ${ }^{[6,12]}$

\section{References}

1. Latta A, Rampton T, Rosemann J, et al. Snapshots reflecting the lives of siblings of children with autism spectrum disorders. Child Care Health Dev 2013;40(4):515-524. [http://dx.doi.org/10.1111/cch.12100].

2. McHugh M. Special Siblings: Growing up with Someone with a Disability. Baltimore: Paul H Brookes, 2003.

3. Vig S. Young children's object play: A window on development. J Devel Phys Disabil 2007;19(3):201-215. [http://dx.doi.org/10.1007/s10882-0079048-6]

4. Gamble WC, McHale SM. Coping with stress in sibling relationships: A comparison of children with disabled and nondisabled siblings. J Appl Devel Psychol 1989;10:353-373.

5. Opperman S, Alant E. The coping responses of the adolescent siblings of children with severe disabilities. Disabil Rehabil 2003;25(9):441-454. [http:// dx.doi.org/10.1080/0963828031000069735]

6. World Health Organization (WHO). International Classification of Functioning, Disability and Health: Children and Youth Version. Geneva; WHO, 2007.

7. Granlund M, Arvidsson P, Niia A, et al. Differentiating activity and participation of children and youth with disability in Sweden: A third qualifier for the ICFCY? Am J Phys Med Rehabil 2012;91(13):84-96. [http://dx.doi.org/10.1097/ PHM.0b013e31823d5376

8. McCormack J, McLeod S, McAllister L, Harrison LJ. A systematic review of the association between childhood speech impairment and participation across the lifespan. Int J Speech-Lang Path 2009;11(2):155-170. [http://dx.doi. org/10.1080/17549500802676859]

9. McLeod S, Threats TT. The ICF-CY and children with communication disabilities. Int J Speech-Lang Path 2008;10(1-2):92-109. [http://dx.doi. org/0.1080/17549500701834690]

10. Thomas-Stonell N, Washington K, Oddson B, Robertson B, Rosenbaum P. Measuring communicative participation using the FOCUS(C): Focus on the Outcomes of Communication Under Six. Child Care Health Dev 2013;39(4):474-480. [http://dx.doi.org/10.1111/cch.12049]

11. Raghavendra P. Participation of children with disabilities: Measuring subjective and objective outcomes. Child Care Health Dev 2013;39(4):461-465. [http:// dx.doi.org/10.1111/cch.12084]

12. Adolfsson M. Applying the ICF-CY to identify children's everyday life situations: A step towards participation-focused code sets. Int J Soc Welf 2013;22(2):195206. [http://dx.doi.org/10.1111/j.1468-2397.2012.00876.x]

13. Powell TH, Gallagher PA. Brothers \& Sisters: A Special Part of Exceptional Families. 2nd ed. Baltimore: Paul H Brookes, 1993.

14. Hansen $M$. The attitudes of typically developing children towards participation with their siblings with severe speech and language disabilities. Unpublished Master's thesis in Augmentative and Alternative Communication. Pretoria: University of Pretoria, 2011.

15. Bornman J, Murphy J. Using the ICF in goal setting: Clinical application using Talking Mats. Disabil Rehabil Assist Tech 2006;1(3):145-154. [http://dx.doi.org /10.1080/17483100612331392745]

16. World Medical Association. Declaration of Helsinki - Ethical principles for medical research involving human participants. Seoul; World Medical Association, 2008. [http://dx.doi.org/10.4103/0022-3859.52846]

17. Abramovitch R, Corter C, Pepler DJ, Stanhope L. Sibling and peer interaction: A final follow-up and comparison. Child Dev 1986;57(1):217-229.

18. Caro P, Derevensky JL. An exploratory study using the Sibling Interaction Scale: Observing interactions between siblings with and without disabilities. Educ Treat Children 1997;20(4):383-403.

19. Almqvist L, Uys CJE, Sandberg A. The concepts of participation, engagement and flow: A matter of creating optimal play experiences. S Afr J Occup Ther 2007;37(3):8-13. 